\title{
BLOOD FLOW THROUGH EACH LUNG IN MAN DURING UNILATERAL HYPOXIA ${ }^{1}$
}

\author{
By A. P. FISHMAN,2 A. HIMMELSTEIN, H. W. FRITTS, JR.,? AND A. COURNAND \\ (From the Department of Medicine, Columbia University, College of Physicians and Surgeons, and the \\ Cardio-Pulmomary Laboratory of the First Medical and Chest Services (Columbia \\ University Division), Bellevue Hospital, New York, N. Y.)
}

(Submitted for publication November 19, 1954 ; accepted December 30, 1954)

It is well established that pulmonary hypertension may be elicited in man by reducing the oxygen content of the inspired air. The mechanisms involved in this response to acute hypoxia, and the role of the individual segments of the pulmonary vascular tree in effecting this rise in pulmonary arterial pressure, are currently under investigation. In order to further analyze this phenomenon, a method has been developed for the separate measurement of blood flow through each lung in man. This method consists of a combination of (a) bronchospirometry, with each lung breathing a specifically selected oxygen mixture, (b) cardiac catheterization, and (c) arterial cannulation; this makes possible the application of the Fick principle, not only for the measurement of total blood flow, but also of blood flow through each lung.

Previous attempts to partition pulmonary blood flow in man have been indirect, and have involved many assumptions (1). It is the purpose of this paper to 1) describe a method based on more direct data, and 2) present the results of studies concerning the effects of unilateral hypoxia upon the pulmonary circulation in man.

\section{METHODS}

\section{Principle of the method}

The principle of the method may be outlined as follows: a) Oxygen uptake by each lung is determined by bronchospirometry; b) the oxygen content of the mixed venous blood going to both lungs is determined by sampling through a catheter placed in the pulmonary artery; c) the

1 This investigation was supported (in part) by a research grant (PHS Grant H-833 [C]) from the National Heart Institute of the National Institutes of Health, Public Health Service, with additional support from the Life Insurance Medical Research Fund and the American Heart Association.

2 Established Investigator of the American Heart Association.

- Fellow, Life Insurance Medical Research Fund. oxygen content of peripheral arterial blood, representing a mixture of blood leaving both lungs, is determined by analysis of a sample obtained through the indwelling arterial needle; d) the oxygen content of pulmonary venous blood leaving one of the two lungs, hereafter designated as lung $\mathrm{H}$, is fixed at 100 per cent of capacity by the breathing of a gas mixture of oxygen in nitrogen somewhat higher in oxygen content than ambient air. This inspired gas mixture is capable of fully saturating with oxygen the hemoglobin in pulmonary venous blood, without unduly increasing the amount of oxygen carried in physical solution. The amount of oxygen in solution in the blood of a normal subject while breathing a mixture of 33 per cent oxygen in nitrogen will be approximately $0.5 \mathrm{ml}$. per 100 ml., and while breathing 25 per cent oxygen in nitrogen will be $0.3 \mathrm{ml}$. per $100 \mathrm{ml}$. These figures correspond within $0.2 \mathrm{ml}$. per $100 \mathrm{ml}$. to the amount of oxygen in physical solution when arterial blood is equilibrated in vitro with ambient air. Hence, the oxygen capacity of the arterial blood $\left(\mathrm{CAPa}_{2}\right)$ is substituted for the oxygen content of venous blood leaving lung $\mathrm{H}\left(\mathrm{CPVO}_{2}=\mathrm{CAPaO}_{2}\right)$.

With the data thus obtained it is then possible to calculate 1) the minute volume of blood flowing through both lungs ( $\left.\dot{Q}_{\mathrm{r}}\right)$, and 2) the minute volume of blood flowing through lung $H,\left(\dot{Q}_{H}\right)$, by employing two separate equations based on the Fick principle. The minute flow ( $\dot{Q}_{\mathrm{L}}$ ) through the other lung (lung L), which breathes either ambient air or a mixture of oxygen in nitrogen lower than 21 per cent, is then calculated as the difference between $\dot{Q}_{\mathrm{T}}$ and $\dot{Q}_{\mathrm{H}}$. In contrast to indirect methods previously employed, no attempt is made to estimate the oxygen content of the pulmonary venous blood $\left(\mathrm{CPV}_{32}\right)$ of the hypoxic lung.

The formulae used and their application to the problem of unilateral hypoxia, are illustrated in Figure 1.

\section{Calculations and their justification}

1. Total pulmonary blood flow. Total pulmonary blood flow per minute ( $\dot{Q}_{\mathrm{T}}$ ) is equal to the total oxygen uptake of both lungs per minute $\left(\dot{V}_{\mathrm{O}_{\mathbf{B}_{\mathrm{B}}}}+\dot{\mathrm{V}}_{\mathrm{O}_{2 \mathrm{~L}}}\right)$, divided by the corresponding arterial-mixed venous blood oxygen difference $\left(\mathrm{CaO}_{2}-\mathrm{C}_{\mathrm{v}_{2}}\right)$. This differs from the usual method of determining pulmonary blood flow only in that oxygen uptake for each lung is determined separately, and then summated.

2. Blood flow through the lung breathing the higher oxygen mixture (lung $H$ ). Since the oxygen uptake of the highoxygen lung per minute $\left(\dot{V}_{\mathrm{O}_{\mathrm{H}}}\right)$, and the oxygen content of mixed venous blood $\left(\mathrm{C}_{\mathrm{v}_{2}}\right)$ have been determined in the process of measuring total minute pulmonary blood flow 


\section{VOLUME OF BLOOD FLOW \\ THROUGH BOTH LUNGS( $\left.Q_{T}\right)$ AND EACH LUNG $\left(\delta_{H}, \delta_{L}\right)$ DURING UNILATERAL HYPOXIA}

$$
\begin{gathered}
\dot{Q}_{T}-\frac{\left(\dot{V}_{O_{2}}+\dot{V}_{O_{2}}\right)}{\left(C_{2 O_{2}}-C_{O_{2}}\right)} \\
\dot{Q}_{H}=\frac{\dot{V}_{O_{2}}}{\left(C A P_{O_{2}}-C_{O_{2}}\right)} \quad \dot{Q}_{L}=\dot{Q}_{T}-\dot{Q}_{H}
\end{gathered}
$$
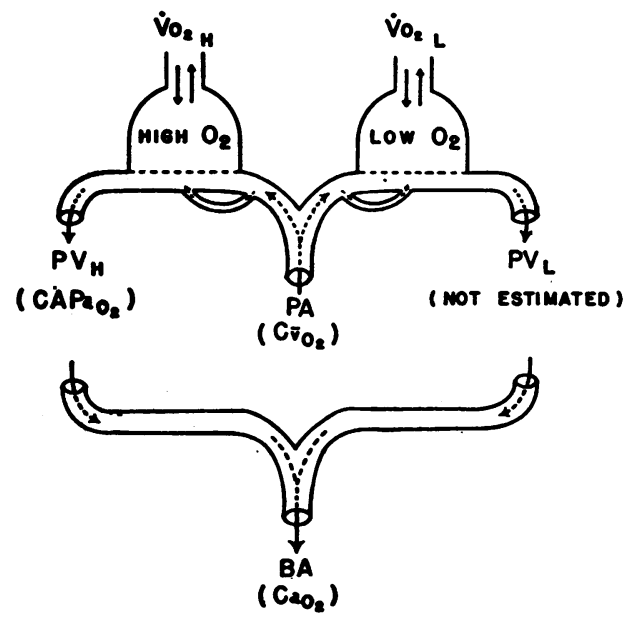

Fig. 1. Scheyatic Representation of the Methods and Formulae for the Determination of TOtal aND Unilateral Pulmonary Blood Flows

For description, see text.

( $\left.\dot{Q}_{\mathrm{r}}\right)$, the only remaining unknown for the calculation of

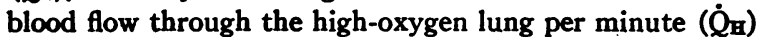
by the Fick principle, is the oxygen content of pulmonary venous blood leaving this lung ( $\mathrm{CPV}_{\mathrm{BH}}$ ).

It was demonstrated on the day before the study, by brachial artery puncture, direct sampling, and chemical analysis for oxygen content and capacity of whole blood, that breathing a mixture of 25 per cent oxygen in nitrogen resulted, in all but one of our subjects, in an oxygen saturation $\left(\frac{O_{2} \text { content }}{O_{2} \text { capacity }} \times 100\right)$ of peripheral arterial blood, of not less than 99 per cent, and not greater than 100 per cent. In only one subject was it necessary to resort to inspired gas mixture containing 33 per cent oxygen in nitrogen to obtain such an oxygen saturation. After the preliminary determination of the composition of the inspired gas mixture necessary to accomplish this degree of arterial blood oxygen saturation, the mixture was subsequently administered via bronchospirometry tube, on the day of the experiment, to lung $\mathrm{H}$ as its inspired gas; the oxygen capacity of the arterial blood ( $\mathrm{CAPaO}$ ) was hereafter substituted as equivalent to the oxygen content of pulmonary venous blood leaving lung $\mathrm{H}$ ( $\left.\mathrm{CPVO}_{2 \mathrm{H}}\right)$.

3. Blood flow through the lung breathing the lower oxygen mixture (lung $L$ ). As indicated above, blood flow through this lung per minute $\left(\dot{Q}_{\mathrm{L}}\right)$ is determined as the difference

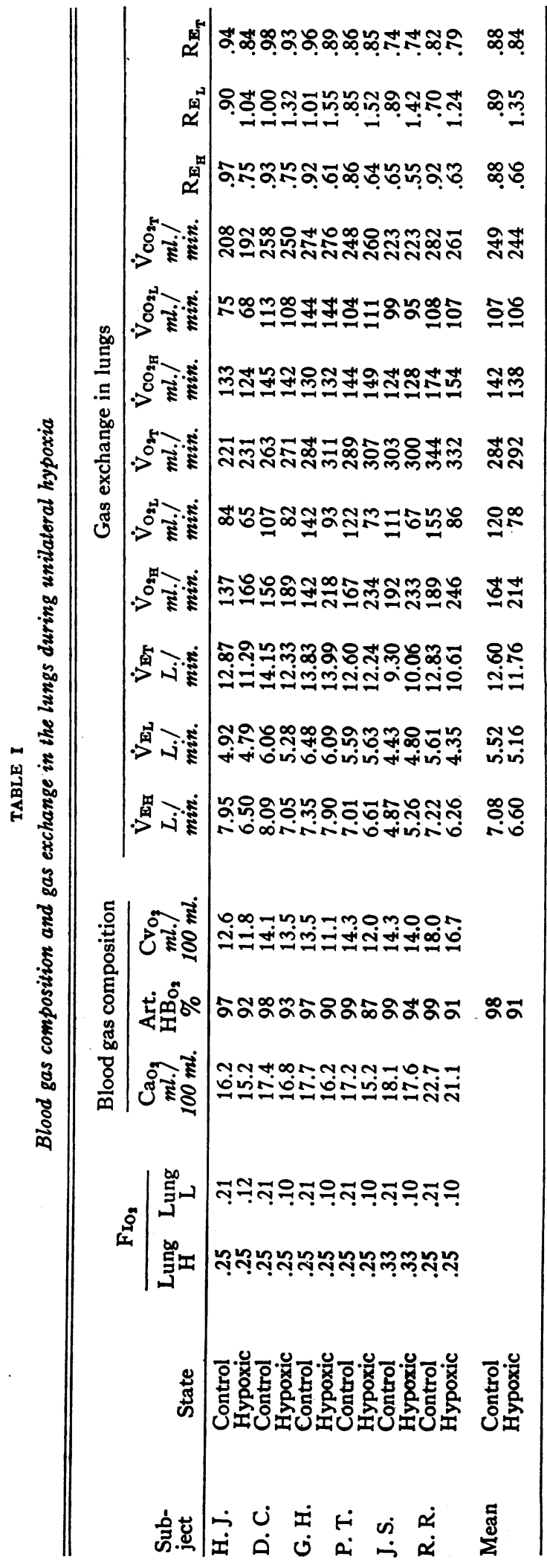


between total pulmonary blood flow $\left(\dot{Q}_{\mathrm{T}}\right)$ and blood flow through the high-oxygen lung $\left(\dot{Q}_{\mathrm{B}}\right)$.

\section{Experimental procedure and subjects}

The experimental procedure was attempted nine times; six studies were successfully completed. Our observations were confined to male subjects with sharply circumscribed, unilateral pulmonary lesions, i.e., either arrested minimal pulmonary tuberculosis prior to segmental resection, or a discrete pulmonary nodule due to bronchogenic carcinoma. All were in the post-absorptive state without premedication.

Cardiac catheterization, with placement of the catheter tip in the main pulmonary artery, was done in the usual manner. The tracheo-bronchial double lumen tube, usually of the Carlens model, was then introduced under local anesthesia, immediately following the intravenous administration of atropine sulfate, gr. 1/150. The position of the tube was verified by fluoroscopy and the presence of leaks checked by attempting to force air from one spirometer into the other following inflation of the occluding bronchospirometric cuffs. The three unsuccessful attempts were due to improper placement of the bronchospirometry tubes, or to small leaks around the bronchial cuff, resulting in the incomplete separation of inspired and expired gas from the two lungs as demonstrated by analysis of expired gas. The indwelling needle was introduced into a brachial artery following the placement of both the cardiac catheter and the tracheobronchial double lumen tube.

Each inspired gas mixture was breathed by means of a separate open circuit. Each circuit consisted of a tank containing the specific mixture of oxygen in nitrogen, an anesthesia bag interposed between the reducing valve and a low-resistance, three-way valve connected with one of the two lumens of the tracheo-bronchial tube, and a collecting spirometer for measurement of minute ventilation $\left(\dot{V}_{E}\right)$, and sampling of expired gas. During the control period, the normal lung breathed the hyperoxic mixture $\left(\mathrm{F}_{\mathrm{O}_{2}}=.25\right.$ or .33$)$; the other lung breathed ambient air $\left(\mathrm{F}_{\mathrm{I}_{2}}=.21\right)$. After at least 10 minutes of equilibration, expired gas, arterial and mixed venous blood samples were simultaneously collected, over corresponding time periods, for determination of pulmonary blood flow. Following a second control period the low oxygen mixture $\left(\mathrm{F}_{\mathrm{I}_{2}}=.10\right.$ or .12) was substituted, without the patient's knowledge, for ambient air; the hyperoxic mixture to the "normal" lung was continued. After 15, and again, 20 to 25 minutes of re-equilibration, blood and expired gas samples were drawn for determination of pulmonary blood flows. In two patients, a final control study was repeated, using the initial gas mixtures, beginning approximately 10 to 20 minutes after cessation of unilateral hypoxia. Pulmonary arterial pressures were obtained using Statham strain gauge pressure transducers, a multi-channel apparatus with high sensitivity carrier amplifiers, and photographic recording of the cathode-ray images. Systolic and diastolic pressures were measured during two complete respiratory cycles and were averaged; mean pressures were obtained by planimetric integration of the corresponding areas.

Oxygen content and capacity of whole blood were determined by the Van Slyke-Neill apparatus; the fractions of oxygen and carbon dioxide in inspired and expired gas were determined by the $0.5 \mathrm{ml}$. micro-Scholander apparatus. All analyses were done in duplicate. From the analyses of inspired and expired gas, oxygen uptake, carbon dioxide output and respiratory exchange ratios were calculated for each lung and for both lungs.

TABLE II

Pulmonary blood flow and pulmonary arterial pressure during unilateral hypoxia

\begin{tabular}{|c|c|c|c|c|c|c|c|c|c|c|}
\hline \multirow[b]{3}{*}{$\begin{array}{l}\text { Sub- } \\
\text { ject }\end{array}$} & \multirow[b]{3}{*}{ State } & \multirow{2}{*}{\multicolumn{2}{|c|}{$\mathrm{Fi}_{\mathrm{O}_{2}}$}} & \multicolumn{4}{|c|}{ Pulmonary blood flow } & \multicolumn{3}{|c|}{ Pulm. art. pressure } \\
\hline & & & & \multirow{2}{*}{$\begin{array}{l}\dot{Q}_{\mathrm{H}} \\
\dot{L} . / \\
\min .\end{array}$} & \multirow{2}{*}{$\begin{array}{c}\dot{\mathrm{Q}}_{\mathrm{L}} \\
\dot{L} . / \\
\min .\end{array}$} & \multirow{2}{*}{$\begin{array}{c}\dot{Q}_{\mathrm{T}} \\
\text { min. }\end{array}$} & \multirow[b]{2}{*}{$\frac{\dot{\mathrm{Q}}_{\mathrm{L}}}{\dot{\mathrm{Q}}_{\mathrm{T}}} \times 100$} & \multirow{2}{*}{$\begin{array}{c}\mathrm{s} \\
\mathrm{mm} . \\
\mathrm{Hg}\end{array}$} & \multirow{2}{*}{$\begin{array}{c}\mathrm{d} \\
\mathrm{mm} . \\
\mathrm{Hg}\end{array}$} & \multirow{2}{*}{$\begin{array}{c}\mathrm{m} \\
\mathrm{mm} \\
\mathrm{Hg}\end{array}$} \\
\hline & & $\begin{array}{c}\text { Lung } \\
\mathrm{H}\end{array}$ & $\begin{array}{l}\text { Lung } \\
\text { L }\end{array}$ & & & & & & & \\
\hline H. J. & $\begin{array}{l}\text { Control } \\
\text { Hypoxic }\end{array}$ & .25 & $\begin{array}{l}.21 \\
.12\end{array}$ & $\begin{array}{l}3.38 \\
3.47\end{array}$ & $\begin{array}{l}2.79 \\
3.25\end{array}$ & $\begin{array}{l}6.17 \\
6.72\end{array}$ & $\begin{array}{l}45 \\
48\end{array}$ & $\begin{array}{l}20 \\
19\end{array}$ & $\begin{array}{r}10 \\
8\end{array}$ & $\begin{array}{l}15 \\
14\end{array}$ \\
\hline D. C. & $\begin{array}{l}\text { Control } \\
\text { Hypoxic }\end{array}$ & $\begin{array}{l}.25 \\
.25\end{array}$ & $\begin{array}{l}.21 \\
.10\end{array}$ & $\begin{array}{l}4.18 \\
4.27\end{array}$ & $\begin{array}{l}3.78 \\
4.32\end{array}$ & $\begin{array}{l}7.96 \\
8.59\end{array}$ & $\begin{array}{l}47 \\
50\end{array}$ & $\begin{array}{l}27 \\
26\end{array}$ & $\begin{array}{l}14 \\
14\end{array}$ & $\begin{array}{l}20 \\
20\end{array}$ \\
\hline G. H. & $\begin{array}{l}\text { Control } \\
\text { Hypoxic }\end{array}$ & $\begin{array}{l}.25 \\
.25\end{array}$ & $\begin{array}{l}.21 \\
.10\end{array}$ & $\begin{array}{l}3.87 \\
3.07\end{array}$ & $\begin{array}{l}2.98 \\
3.03\end{array}$ & $\begin{array}{l}6.85 \\
6.10\end{array}$ & $\begin{array}{l}44 \\
50\end{array}$ & $\begin{array}{l}24 \\
25\end{array}$ & $\begin{array}{l}9 \\
9\end{array}$ & $\begin{array}{l}15 \\
16\end{array}$ \\
\hline P. T. & $\begin{array}{l}\text { Control } \\
\text { Hypoxic }\end{array}$ & $\begin{array}{l}.25 \\
.25\end{array}$ & $\begin{array}{l}.21 \\
.10\end{array}$ & $\begin{array}{l}4.17 \\
3.94\end{array}$ & $\begin{array}{l}5.79 \\
5.67\end{array}$ & $\begin{array}{l}9.96 \\
9.61\end{array}$ & $\begin{array}{l}58 \\
59\end{array}$ & $\begin{array}{l}18 \\
19\end{array}$ & $\begin{array}{l}8 \\
7\end{array}$ & $\begin{array}{l}14 \\
15\end{array}$ \\
\hline J.S. & $\begin{array}{l}\text { Control } \\
\text { Hypoxic }\end{array}$ & $\begin{array}{l}.33 \\
.33\end{array}$ & $\begin{array}{l}.21 \\
.10\end{array}$ & $\begin{array}{l}4.73 \\
5.43\end{array}$ & $\begin{array}{l}3.10 \\
2.91\end{array}$ & $\begin{array}{l}7.83 \\
8.34\end{array}$ & $\begin{array}{l}40 \\
35\end{array}$ & $\begin{array}{l}16 \\
19\end{array}$ & $\begin{array}{l}8 \\
9\end{array}$ & $\begin{array}{l}13 \\
14\end{array}$ \\
\hline R. R. & $\begin{array}{l}\text { Control } \\
\text { Hypoxic }\end{array}$ & $\begin{array}{l}.25 \\
.25\end{array}$ & $\begin{array}{l}.21 \\
.10\end{array}$ & $\begin{array}{l}3.63 \\
3.69\end{array}$ & $\begin{array}{l}3.70 \\
3.85\end{array}$ & $\begin{array}{l}7.33 \\
7.54\end{array}$ & $\begin{array}{l}50 \\
51\end{array}$ & $\begin{array}{l}21 \\
19\end{array}$ & $\begin{array}{l}9 \\
8\end{array}$ & $\begin{array}{l}15 \\
14\end{array}$ \\
\hline Mean & $\begin{array}{l}\text { Control } \\
\text { Hypoxic }\end{array}$ & & & $\begin{array}{l}3.99 \\
3.98\end{array}$ & $\begin{array}{l}3.70 \\
3.84\end{array}$ & $\begin{array}{l}7.69 \\
7.82\end{array}$ & $\begin{array}{l}48 \\
49\end{array}$ & $\begin{array}{l}21 \\
21\end{array}$ & $\begin{array}{r}10 \\
9\end{array}$ & $\begin{array}{l}15 \\
16\end{array}$ \\
\hline
\end{tabular}




\section{RESULTS}

The data concerning the blood gas composition and the gas exchange in the lungs of the six subjects are presented in Table I. The figures listed for the control and unilateral hypoxia periods are the average of two determinations, except in subjects G. H. and J.S., where only one study was performed during unilateral hypoxia. The values for total pulmonary blood flow ( $\left.\dot{Q}_{\mathrm{T}}\right)$ and for the blood flow through each lung $\left(\dot{Q}_{\mathrm{H}}\right.$ and $\dot{Q}_{\mathbf{L}}$ ) calculated from these data are presented in Table II, together with the corresponding pulmonary arterial pressures. Table III contains the time sequence of the individual studies, as well as the measurements of the total blood flow $\left(\dot{Q}_{\mathrm{T}}\right)$ and of blood flow through the hypoxic lung ( $\left.\hat{Q}_{\mathbf{L}}\right)$.

\section{Control periods}

During these periods, the mean arterial blood oxyhemoglobin saturation was 98 per cent, rang-

TABLE III

Successive determinations of total blood flow, and blood flow through one lung prior to, and during unilateral hypoxia

\begin{tabular}{|c|c|c|c|c|c|}
\hline Subject & State & $\begin{array}{l}\text { Time of } \\
\text { expos. } \\
\text { min. }\end{array}$ & 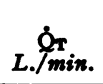 & L. $\dot{q}_{\mathrm{min}}$ & $\frac{\dot{\mathbf{Q}}_{\mathrm{L}}}{\dot{\mathbf{Q}}_{\mathrm{T}}} \times 10$ \\
\hline \multirow[t]{2}{*}{ H. J. } & Control & $\begin{array}{l}10 \\
15\end{array}$ & $\begin{array}{l}5.75 \\
6.58\end{array}$ & $\begin{array}{l}2.67 \\
2.91\end{array}$ & $\begin{array}{l}46 \\
44\end{array}$ \\
\hline & Hypoxic & $\begin{array}{l}15 \\
20\end{array}$ & $\begin{array}{l}6.56 \\
6.88\end{array}$ & $\begin{array}{l}3.05 \\
3.40\end{array}$ & $\begin{array}{l}46 \\
49\end{array}$ \\
\hline \multirow[t]{3}{*}{ D. C. } & Control & 15 & 8.18 & 4.24 & 52 \\
\hline & Hypoxic & $\begin{array}{l}15 \\
25\end{array}$ & $\begin{array}{l}7.58 \\
9.60\end{array}$ & $\begin{array}{l}3.90 \\
4.74\end{array}$ & $\begin{array}{l}51 \\
49\end{array}$ \\
\hline & Control & 15 & 7.76 & 3.33 & 43 \\
\hline \multirow[t]{2}{*}{ G. H. } & Control & $\begin{array}{l}10 \\
15\end{array}$ & $\begin{array}{l}6.78 \\
6.91\end{array}$ & $\begin{array}{l}2.49 \\
3.48\end{array}$ & $\begin{array}{l}37 \\
50\end{array}$ \\
\hline & Hypoxic & 15 & 6.10 & 3.03 & 50 \\
\hline \multirow[t]{2}{*}{ P. T. } & Control & $\begin{array}{l}10 \\
15\end{array}$ & $\begin{array}{r}9.74 \\
10.18\end{array}$ & $\begin{array}{l}5.24 \\
6.34\end{array}$ & $\begin{array}{l}54 \\
62\end{array}$ \\
\hline & Hypoxic & $\begin{array}{l}15 \\
20\end{array}$ & $\begin{array}{l}9.88 \\
9.34\end{array}$ & $\begin{array}{l}5.72 \\
5.62\end{array}$ & $\begin{array}{l}58 \\
60\end{array}$ \\
\hline \multirow[t]{3}{*}{ J.S. } & Control & 10 & 8.00 & 2.89 & 36 \\
\hline & Hypoxic & 15 & 8.34 & 2.91 & 35 \\
\hline & Control & 10 & 7.67 & 3.32 & 43 \\
\hline \multirow[t]{2}{*}{ R. R. } & Control & $\begin{array}{l}10 \\
15\end{array}$ & $\begin{array}{l}7.75 \\
6.90\end{array}$ & $\begin{array}{l}4.12 \\
3.27\end{array}$ & $\begin{array}{l}52 \\
48\end{array}$ \\
\hline & Hypoxic & $\begin{array}{l}15 \\
25\end{array}$ & $\begin{array}{l}7.35 \\
7.72\end{array}$ & $\begin{array}{l}3.55 \\
4.14\end{array}$ & $\begin{array}{l}48 \\
54\end{array}$ \\
\hline
\end{tabular}

ing from 97 to 99 per cent. Total minute ventilation $\left(\dot{V}_{E_{T}}\right)$, as well as the ventilation of each lung $\left(\dot{V}_{E_{H}}, \dot{V}_{E_{L}}\right)$ exceeded that observed in normal subjects under resting conditions.

The total oxygen uptake $\left(\dot{\mathrm{V}}_{\mathrm{O}_{2 \mathrm{~T}}}\right)$ was elevated to a mean of $284 \mathrm{ml}$. per min., which corresponds to an average increase in metabolic rate of approximately 25 per cent over and above predicted basal values. The total carbon dioxide production $\left(\dot{V}_{\mathrm{O}_{2 \mathrm{~T}}}\right)$ was increased proportionally, and the average respiratory exchange ratio for both lungs ( $R_{E_{T}}$ ) was 0.88 . The lung receiving the hyperoxic mixture (lung $H$ ), usually the right lung, contributed 58 per cent of the total oxygen uptake and 57 per cent of the total carbon dioxide production.

The total cardiac output $\left(\dot{Q}_{\mathrm{T}}\right)$ was greater than normal, averaging 7.69 liters per minute, or 33 per cent above the predicted figure for normal resting individuals under standard metabolic conditions. The blood flow through the lung breathing ambient air $\left(\dot{Q}_{\mathrm{L}}\right)$ was 48 per cent of the total cardiac output. As seen in Table III, the differences between total blood flow during two control periods were small, regardless of whether the periods were in succession or separated by an intervening period of unilateral hypoxia. The largest difference between control periods was 14 per cent. The proportion of blood flowing through lung $\mathrm{L}\left(\frac{\dot{Q}_{\mathrm{L}}}{\dot{Q}_{\mathrm{T}}} \times 100\right)$ was also constant, varying by less than 10 per cent in all but one patient (G. H.) where it reached 13 per cent.

\section{Unilateral hypoxia}

After exposure of lung $\mathrm{L}$ to the low oxygen mixture, the mean arterial oxyhemoglobin saturation decreased to 91 per cent. Neither the mean total minute ventilation $\left(\dot{V}_{E_{H}}, \dot{V}_{E_{L}}\right)$, the total oxygen uptake $\left(\dot{\mathrm{V}}_{\mathrm{O}_{2 \mathrm{~T}}}\right)$, the total carbon dioxide production $\left(\dot{\mathrm{V}}_{\mathrm{C}_{2 \mathrm{~T}}}\right)$, nor the production of carbon dioxide by each lung $\left(\dot{V}_{\mathrm{CO}_{2 \mathrm{~B}}}\right),\left(\dot{\mathrm{V}}_{\mathrm{CO}_{2 \mathrm{~L}}}\right)$ differed significantly from corresponding control values (Table I). However, the mean oxygen uptake of the low oxygen lung $\left(\dot{\mathrm{V}}_{\mathrm{O}_{2 \mathrm{~L}}}\right)$ decreased from 120 to $78 \mathrm{ml}$. per min., i.e., from 42 to 27 per cent of $\dot{V}_{O_{2 T}}$, and the oxygen uptake of the high oxygen lung $\left(\dot{\mathrm{V}}_{\mathrm{O}_{2 \mathrm{H}}}\right)$ correspondingly increased from 164 to $218 \mathrm{ml}$. per min., or from 58 to 73 per cent of $\dot{V}_{\mathbf{O}_{2 T}}$. The constant carbon dioxide production in the face of diminished oxy- 
gen uptake by the hypoxic lung (lung L) resulted in an augmented respiratory exchange ratio $\left(R_{E_{L}}\right)$ with a mean of 1.35 ; conversely, the hyperoxic lung (lung $\mathrm{H}$ ) with a relative increase in oxygen uptake and constant carbon dioxide production, had a diminished mean respiratory exchange ratio $\left(R_{E_{H}}\right)$ of .66 , as compared to the mean control $R_{E_{H}}$, of .88 .

In individual subjects, differences in total and unilateral blood flow between control and experimental periods were slight and inconsistent. Neither mean total blood flow ( $\dot{Q}_{\mathbf{T}}$ ) nor the partition of blood between the two lungs $\left(\dot{Q}_{\mathrm{H}}, \dot{\mathrm{Q}}_{\mathrm{L}}\right)$ altered during unilateral hypoxia (Table II). It is noteworthy also that in the four patients in whom two studies were made during unilateral hypoxia (Table III), the proportion of total blood flow through the hypoxic lung $\left(\frac{\dot{Q}_{\mathrm{L}}}{\dot{\mathrm{Q}}_{\mathrm{T}}} \times 100\right)$, did not vary by more than 6 per cent for periods up to 25 minutes.

Pulmonary arterial pressures were recorded in all subjects. The tracings were characterized by marked respiratory swings. However, in sharp contrast with the results of studies in man, which demonstrate that the breathing of similar hypoxic mixtures by both lungs consistently cause pulmonary hypertension, pulmonary arterial systolic, diastolic and mean pressures remained at their control levels.

\section{DISCUSSION}

This investigation of the effects of unilateral pulmonary hypoxia upon ipsilateral pulmonary blood flow, has several aspects which merit further comment. They are discussed in the following order:

1) The validity of the use of the Fick principle for the measurement of the pulmonary blood flow under the particular experimental conditions of the study ; 2) the validity of the assumption that pulmonary venous blood leaving the hyperoxic lung continues to be fully saturated with oxygen during the period of contralateral hypoxia; 3 ) the physiologic basis for (a) the reduction in oxygen uptake by the lung breathing the hypoxic gas mixture and (b) for the increase in oxygen uptake by the lung breathing the hyperoxic gas mixture, despite an unchanged distribution of pulmonary blood flow; 4) the site and mecha- nism of action of the hypoxic stimulus upon the pulmonary vascular bed; 5) a comparison of our results with those reported by others investigating the same problem in animals and man, and 6) the potentiality of this new method for the evaluation, in man, of the pharmacologic effects of various substances upon the blood flow through each lung.

\section{1) The validity of the use of the Fick principle in these experiments}

Potential limitations in the application of the Fick principle to the measurement of pulmonary blood flow during acute systemic hypoxia have recently been described $(2,3)$. These considerations, based primarily upon theoretical analyses of cyclic changes in respiration and circulation, have been put to experimental test $(4,5)$ and found to constitute only a slight source of potential error in a "steady state" of respiration and circulation. In particular, they have little applicability to the present study despite unilateral breathing of a mixture of 10 per cent oxygen in nitrogen, since (a) the degree of systemic arterial hypoxemia was slight, averaging 91 per cent oxyhemoglobin saturation during experimental periods, (b) the changes from control values, in mixed venous blood oxygen content and in total oxygen uptake, were small, and (c) variations from the control state of ventilatory, circulatory, and metabolic equilibrium, achieved during the stress of bronchospirometry, were at a minimum. The data show that even though the patients were not "basal" during the course of the consecutive control and hypoxic periods, the various cardio-pulmonary functions, including cardiac output, total minute ventilation, oxygen uptake, carbon dioxide output and respiratory exchange ratio for both lungs, remained stable, thus satisfying criteria previously suggested for the "steady state" (6). Account was also taken of the possibility that the injection of atropine sulfate, used in order to minimize bronchial secretions, could induce a changing state of the circulation, as the effect of the drug waxed and then waned during the course of successive measurements. However, tachycardia persisted unchanged during the entire procedure, and therefore a varying state of the circulation due to atropine sulfate, seems unlikely. 


\section{2) Validity of the assumption that pulmonary venous blood leaving the hyperoxic lung is fully saturated with oxygen during the period of contralateral hypoxia}

A basic requirement of the measurement of blood flow through each lung is that pulmonary venous blood leaving the hyperoxic lung continues to be fully saturated with oxygen. Since, during the present experiments with unilateral hypoxia, the oxygen uptake by the hyperoxic lung increases whereas minute ventilation and carbon dioxide production remain essentially unchanged, the possibility exists that the oxygen content of pulmonary venous blood on the hyperoxic side might not reach 100 per cent of capacity, thereby obscuring a shift of blood from the hypoxic side. This possibility was tested by calculations based upon the experimental data; a sample calculation is presented for patient $H$. J.

a) In this patient, arterial blood $\mathrm{P}_{\mathrm{CO}_{2}}=40$ $\mathrm{mm}$. $\mathrm{Hg}$ during the control period, and remained unchanged during unilateral hypoxia.

b) Substituting in the alveolar gas equation the values obtained during the control periods, $R_{E_{H}}=R_{A_{H}}=.97$ (Table I), and $P_{a_{2 H}}=40$ $\mathrm{mm}$. $\mathrm{Hg}$, it is found that $\mathrm{PAO}_{2 \mathrm{H}}=139 \mathrm{~mm}$. $\mathrm{Hg}$.

c) Substituting then the values obtaining during unilateral hypoxia, $R_{E_{H}}=R_{A_{H}}=.75$ (Table I) and $\mathrm{PaCO}_{2}=\mathrm{PACO}_{2 \mathrm{H}}=40 \mathrm{~mm}$. $\mathrm{Hg}$, it is found that $\mathrm{PAO}_{2 \mathrm{H}}=130 \mathrm{~mm}$. Hg. This tension is adequate for full saturation of pulmonary venous blood with oxygen.

d) However, the $\mathrm{P}_{\mathrm{CO}_{2}}$ in the pulmonary venous blood leaving each lung may conceivably be different during the hypoxic period from the $\mathrm{P}_{\mathrm{CO}_{2}}$ of the mixed arterial blood and thereby would alter the value for the $\mathrm{P}_{\mathrm{AO}_{2 \mathrm{H}}}$ calculated above. For lung $\mathrm{H}$, it is inconceivable that the $\mathrm{PPV}_{\mathrm{CO}_{2 \mathrm{H}}}$, and therefore the $\mathrm{PACO}_{2 \mathrm{H}}$, should exceed the $\mathrm{P}_{\mathrm{CO}_{2}}$ in mixed venous blood entering the lung, which in this case $=46 \mathrm{~mm}$. $\mathrm{Hg}$. Substituting, therefore, this latter value in the alveolar gas equation for lung $\mathrm{H}$ during contralateral hypoxia, it is found that $\mathrm{P}_{\mathrm{AO}_{2 \mathrm{~B}}}=123 \mathrm{~mm}$. $\mathrm{Hg}$ instead of 130 mm. $\mathrm{Hg}$.

These calculations indicate that the alveolar oxygen tension, applied to a particularly adverse experimental possibility, would nevertheless suffice to achieve full oxygen saturation of pulmo- nary venous blood leaving lung $\mathrm{H}$ during contralateral hypoxia.

Further calculations in the same patient show that a 25 per cent increase in blood flow through the hyperoxic lung during contralateral hypoxia, would result in an oxygen saturation in pulmonary venous blood from lung $\mathrm{H}$ of 95 per cent and a $\mathrm{PACO}_{2}=76 \mathrm{~mm} . \mathrm{Hg}$; the latter figure for alveolar $\mathrm{P}_{\mathrm{CO}_{2}}$ is impossibly high since the $\mathrm{P}_{\mathrm{CO}_{2}}$ of mixed venous blood $=46 \mathrm{~mm}$. $\mathrm{Hg}$.

In conclusion, there seems to be little doubt that under the conditions of these experiments, it is valid to assume that the oxygen saturation of pulmonary venous blood leaving the hyperoxic lung during contralateral hypoxia as well as during the control periods, is equal to the arterial oxygen capacity.

3) The physiologic basis for diminished oxygen uptake and sustained carbon dioxide production by the hypoxic lung, and for the increased oxygen uptake and sustained carbon dioxide production by the hyperoxic lung

The unchanged carbon dioxide production by each lung during unilateral hypoxia is not surprising, in view of the unchanged ventilation and pulmonary circulation. Of interest, however, is the mechanism responsible for the decrease in oxygen uptake by the hypoxic lung, and the augmented oxygen uptake by the hyperoxic lung, despite an unchanged distribution of pulmonary blood flow. Similar observations, during comparable degrees of hypoxia, have previously been made in man (1) and dog (7).

It is generally assumed that the rate of oxygen uptake at the mouth, in a steady state, measures the rate of diffusion of oxygen across the alveolarcapillary interface of lung, which is in turn equal to the product of the oxygen diffusing capacity of the lung $\left(\mathrm{DL}_{\mathrm{O}_{2}}\right)$ and the mean alveolar-pulmonary capillary oxygen pressure gradient (mean $\Delta \mathrm{P}_{\mathrm{O}_{2}}$ ). During acute, but moderate hypoxia at rest, as long as cardiac output and ventilation do not change, the diffusing capacity of the lung is generally believed to remain constant $(6,8)$. The measured decrease in oxygen uptake by the hypoxic lung as well as the increase by the hyperoxic lung in the present experiments must then be due to corresponding change in the mean alveolar-pulmonary capillary oxygen pressure 
gradient (mean $\Delta \mathrm{P}_{\mathrm{O}_{2}}$ ). On the hypoxic side, the diminution in mean $\Delta \mathrm{P}_{\mathrm{O}_{2}}$ is largely due to the decreased $\mathrm{P}_{\mathrm{AO}_{2 \mathrm{I}}}$, caused by the hypoxic inspired gas mixture. Conversely, the increased oxygen uptake on the hyperoxic side may in part be due to an increased initial alveolar-capillary $\mathrm{P}_{\mathrm{O}_{2}}$ gradient caused by a decrease in $\mathrm{C}_{\mathrm{v}_{2}}$ during contralateral hypoxia; in accord with the discussion above, the degree of change in $\mathrm{P}_{\mathrm{AO}_{2 \mathrm{~B}}}$ is presumably slight but not available to direct sampling. The mechanism for widening the initial alveolar capillary $\mathrm{P}_{\mathrm{O}_{2}}$ gradient is further indicated in Table I, which shows that the largest increase in oxygen uptake was associated with the greatest reduction in mixed venous blood oxygen content, and conversely, the increase in oxygen uptake was least in the patients with smallest decrease in mixed venous blood oxygen content.

The following calculations in patient $\mathrm{H}$. J. illustrate and amplify the previous considerations:

For the application of the Bohr graphic integration method to the determination of mean $\Delta \mathrm{P}_{\mathrm{O}_{2}}$ and $\mathrm{DL}_{\mathrm{O}_{2}}$ of the hypoxic lung, it is necessary to calculate a) the oxygen tension of blood leaving the pulmonary capillary bed; b) the mean alveolar oxygen tension; and c) the oxygen tension of mixed venous blood.

a) The oxygen tension of blood leaving lung $L$ $\left(\mathrm{PPV}_{2 \mathrm{~L}}\right)$ during hypoxia. The data from which this value is derived are:

$\dot{Q}_{\mathrm{L}}=3.25 \mathrm{~L}$. per min., $\quad \dot{\mathrm{V}}_{\mathrm{O}_{2}}=65 \mathrm{ml}$. per min., therefore,

$$
\begin{aligned}
\mathrm{CPVO}_{2 \mathrm{~L}}-\mathrm{C}_{\overline{\mathrm{V}}_{2}} \text { (by Fick principle) } & \\
& =2.0 \mathrm{ml} \text {. per } 100 \mathrm{ml} .
\end{aligned}
$$

Since $\mathrm{C}_{\overline{\mathrm{v}}_{2}}=11.8 \mathrm{ml}$. per $100 \mathrm{ml}$., $\mathrm{CPV}_{\mathrm{O}_{2 \mathrm{~L}}}=11.8$ $+2.0 \mathrm{ml} .=13.8 \mathrm{ml}$. per $100 \mathrm{ml}$. and $\mathrm{HB}_{\mathrm{O}_{2}}$ saturation of $\mathrm{PV}_{\mathrm{L}}=83$ per cent. At $\mathrm{pH}=7.40$ using a standard oxyhemoglobin dissociation curve, $\mathrm{PPV}_{\mathrm{O}_{\mathrm{L}}}=49.0 \mathrm{~mm}$. $\mathrm{Hg}$.

b) The mean alveolar oxygen tension $\left(\mathrm{P}_{\mathrm{AO}_{2 \mathrm{~L}}}\right)$. This value is calculated from the alveolar gas equation ignoring the Haldane effect and using $\mathrm{PaCO}_{2}$ for $\mathrm{PACO}_{2}$ and $\mathrm{R}_{E}$ for $\mathrm{R}_{\mathrm{A}}$; (9) $\mathrm{P}_{\mathrm{AO}_{2 L}}=51$ $\mathrm{mm} . \mathrm{Hg}$.

c) The mixed venous blood oxygen tension
$\left(\mathrm{P}_{\mathrm{vO}_{2 \mathrm{~L}}}\right)$. The mixed venous blood $\mathrm{HB}_{\mathrm{O}_{2}}=72$ per cent. At $\mathrm{pH}=7.38, \mathrm{P}_{\overline{\mathrm{v}}_{2}}=38.5 \mathrm{~mm}$. $\mathrm{Hg}$.

d) The mean alveolar-pulmonary capillary oxygen tension gradient (mean $\Delta \mathrm{P}_{\mathrm{O}_{2}}$ ) for lung $L$ during hypoxia. This value obtained by a modification of the Bohr graphic integration method (8) = $5.8 \mathrm{~mm} . \mathrm{Hg}$.

e) The diffusing capacity $\left(\mathrm{DL}_{\mathrm{O}_{2}}\right)$ of lung $L$ during hypoxia. Since $\dot{\mathrm{V}}_{\mathrm{O}_{2}}=60 \mathrm{ml}$. per min., $\mathrm{DL}_{\mathrm{O}_{2}}=\frac{60}{5.8}=10 \mathrm{ml}$. per min. per mm. $\mathrm{Hg}$.

f) The mean alveolar-pulmonary capillary oxygen tension gradient (mean $\Delta \mathrm{P}_{\mathrm{O}_{2}}$ ) for lung $L$ breathing ambient air. Since neither blood flow nor minute ventilation changed during acute hypoxia, the $\mathrm{DL}_{2}$ is assumed to remain unchanged at the two levels of oxygenation. The $\dot{\mathrm{V}}_{\mathrm{O}_{2}}$ while breathing ambient air $=84 \mathrm{ml}$. per min.; the mean $\Delta \mathrm{P}_{\mathrm{O}_{2}}=\frac{84}{10}=8.4 \mathrm{~mm}$. $\mathrm{Hg}$.

g) The mean alveolar-pulmonary capillary oxygen tension gradient (mean $\Delta \mathrm{P}_{\mathrm{O}_{2}}$ ) for lung $H$. Assuming the same $\mathrm{DL}_{\mathrm{O}_{2}}$ for lung $\mathrm{H}$ and lung $\mathrm{L}$, mean $\Delta \mathrm{P}_{\mathrm{O}_{2}}=\frac{137}{10}=13.7 \mathrm{~mm}$. $\mathrm{Hg}$ during control and $\frac{166}{10}=16.6 \mathrm{~mm}$. Hg during contralateral pulmonary hypoxia.

The values for total $\mathrm{DL}_{\mathrm{O}_{2}}=20 \mathrm{ml}$. per min. per mm. $\mathrm{Hg}$, and the $\mathrm{A}-\mathrm{a} \mathrm{P}_{\mathrm{O}_{2}}$ gradient in lung $\mathrm{L}$ during hypoxia $=2 \mathrm{~mm}$. $\mathrm{Hg}$, are in accord with those previously described for normal subjects $(9,10)$.

\section{4) Site and mode of action of an hypoxic stimulus upon the pulmonary vascular bed}

In our experiments, the hypoxic stimulus, applied to one lung by airway, could have acted upon the conducting airway, alveoli, pulmonary capillaries and post-capillary vascular segments of the lung, to alter resistance to blood flow. Since there was no shift of blood flow from the hypoxic to the contralateral lung during unilateral hypoxia, there is no evidence to indicate an effect of a low oxygen partial pressure upon pulmonary vascular resistance to blood flow. Such an increase in vascular resistance has been postulated by Nisell $(11,12)$ who invoked: a direct effect upon the walls of the pulmonary 
vessels mediated through the circulating hypoxic blood, and an indirect effect on these vessels due to the action of the hypoxic inspired gas mixture upon the intra-pulmonary elastic structures surrounding them. It is apparent that conclusions based on studies with the isolated, heart-lung preparations in dogs and cats are not readily applicable to intact man. Furthermore, in the present experiments, changes in mixed venous blood saturation failed to alter either total pulmonary blood flow or pulmonary arterial pressures, suggesting a negligible effect of acute hypoxia of moderate degree, mediated through the perfusing blood, upon the resistance to blood flow of the precapillary segments of the pulmonary circulation. This observation is further supported by other studies not yet published, but reported elsewhere in 1954 (13) which intend to compare the effect of exercise and of bilateral pulmonary hypoxia upon pulmonary blood flow and pulmonary arterial pressure. From these studies it appears that the degree of oxygen unsaturation in the mixed venous blood has no discernible effect upon the pulmonary vascular resistance in man.

Finally, these experiments do not contribute any information concerning the mechanism recently proposed by Aviado, Ling, Quimby, and Schmidt (14) on controlled perfusion experiments in animals, whereby the effects of acute hypoxia upon the pulmonary circulation were ascribed to stimulation of the carotid body by the hypoxic arterial blood, thereby eliciting vasoconstrictor impulses transmitted by the sympathetic nervous system to the pulmonary vessels. Since the degree of arterial hypoxemia in our studies on man was mild, and since the pulmonary arterial pressures remained unchanged, this hypothesis was not put to test. It is, however, pertinent that in the unpublished studies referred to above (13) surgical excision in man of a considerable portion of the sympathetic innervation of the lung, including both stellate ganglia, one mid-cervical ganglion, and the three upper thoracic sympathetic ganglia and anterior rami bilaterally, had no effect upon the degree of pulmonary arterial hypertension elicited by acute bilateral pulmonary hypoxia.

If systemic arterial hypoxemia does contribute to the elevation of pulmonary arterial pressures, mechanisms other than reflex vasoconstriction of the pulmonary vascular bed may be involved. For example, it is known that acute hypoxia induces vasoconstriction in the systemic circulation, excepting the cerebral and coronary segments. This systemic vasoconstriction suggests the possibility that increase in pulmonary artery pressure may be passive rather than active, involving (a) a shift of blood from the systemic to the pulmonary vessels, thereby causing an increased distension of the pulmonary vessels, and (b) an increased cardiac output (15) into the more distended pulmonary vascular bed. This possibility deserves further exploration.

\section{5) Comparison of present results with those of previous studies}

Our experiments have failed to demonstrate any significant variations in the minute blood flow through each lung during unilateral hypoxia. This is in accord with the conclusions of Jacobaeus and Bruce (1) who studied the problem in man with a method involving rebreathing in a bag, in order to equilibrate a gas mixture with the mixed venous blood, and a number of assumptions which they recognized as open to question. In animals, the results of investigations using rather indirect data have been inconsistent. Thus, in dogs, Moore and Cochran (16) could demonstrate no alteration in the per cent of the total cardiac output perfusing the hypoxic lung during unilateral hypoxia, whereas Rahn and Bahnson (7) calculated a prompt shift of blood flow from the hypoxic to the well-oxygenated lung. The latter studies were handicapped by lack of blood samples, and consequently required extrapolation from values for the respiratory gases in their gaseous phase to their corresponding concentrations in the blood phase. In rabbits, Dirken and Heemstra (17) on the basis of arterial blood oxygen saturation data, adduced evidence for a shift of blood flow from the hypoxic lung to the contralateral, welloxygenated lung occurring only after 8 to 10 hours of continued unilateral hypoxia. It is, therefore, pertinent to emphasize, with respect to the possible influence of the duration of application to the hypoxic stimulus, that our studies during unilateral hypoxia did not last longer than 25 minutes. 
In dogs, using more direct methods of measurement than in the animal experiments cited above, Atwell, Hickam, Pryor, and Page (18) observed a shift of blood flow away from the hypoxic lung in half of the animals within 20 minutes, whereas Peters and Roos (19) observed a shift at 25 minutes in 8 of 11 animals, with gradual return, in some instances, to the control, pre-hypoxic distribution of pulmonary blood flow as the experiments were prolonged. It is difficult to reconcile these conflicting results or to ascribe them to species differences, since there were great variations in (a) the experimental protocols; (b) the types and degrees of anesthesia; (c) the severity of systemic arterial oxyhemoglobin unsaturation, either present during the control periods, or developing during unilateral pulmonary hypoxia, and last, but not least; (d) the lack of attainment or maintenance of a steady state of circulation, respiration, and metabolism. The present experiments were designed to minimize the effect of these specific variables; they demonstrate that in man, during a stable state of respiration and circulation, in the absence of marked systemic arterial hypoxemia, a moderate degree of unilateral pulmonary hypoxia fails to alter pulmonary arterial pressures or flow. Experiments are in progress with the same method in order to test the effect of a greater degree of unilateral hypoxia, and pari passu, of a more marked reduction in systemic arterial oxyhemoglobin saturation.

\section{6) Applicability of the method to the study of other problems}

The method reported herein may be extended to problems other than that of the effects of unilateral pulmonary hypoxia. Among them one may mention 1) the influence of diseases of the lungs upon the partition of pulmonary blood flow and 2) the evaluation of the effects of pharmacodynamic agents, administered by air-way or blood stream upon the ipsilateral pulmonary vascular resistance. For such studies it would seem advantageous to administer to each lung an inspired gas mixture differing notably in oxygen concentration. This would tend to augment the differences between (a) the oxygen uptake of each lung, and (b) the oxygen content and the oxygen capacity of the arterial blood and therefore, minimize the analytic errors attending the application of the Fick principle. Furthermore, the detection of small leaks around the bronchospirometric cuffs, identified by analysis of expired gas and determination of respiratory exchange ratios would be greatly facilitated.

\section{SUMMARY}

1. The techniques of bronchospirometry, cardiac catheterization and cannulation of a peripheral artery have been combined for the application of the Fick principle to the determination of blood flow through each lung in man.

2. The essential features of the method are 1) the separate measurement, by collection of appropriate samples, of the oxygen uptake of each lung, and of the oxygen content of the mixed venous and of the arterial blood, and 2) the assumption that under the conditions of these experiments, the oxygen content of the pulmonary venous blood draining one lung is identical to the oxygen capacity of the arterial blood. This latter assumption was verified by (a) the demonstration of complete arterial blood oxygen saturation, when the subjects in these studies were breathing a mixture of 25 per cent or 33 per cent oxygen in nitrogen with both lungs, and (b) a theoretical analysis of experimental data.

3. During unilateral breathing of hypoxic gas mixtures capable of increasing pulmonary arterial pressure when applied to both lungs, no alteration in either total minute blood flow, or in the distribution of blood flow to each lung was observed. It is therefore concluded that the hypoxic stimulus does not act directly upon either the lung or the post-arteriolar segments of the pulmonary vascular tree to increase pulmonary vascular resistance to blood flow.

4. The physiological factors responsible for the differences in oxygen uptake by both lungs despite the maintenance of pulmonary blood flow during unilateral hypoxia, are discussed.

\section{ACKNOWLEDGMENT}

The authors wish to thank Dr. David Simpson, Dr. Fernando Lahoz, and Mrs. Marianne S. Lester for their help in carrying out these studies, and Dr. D. W. Richards for his interest and helpful suggestions. 


\section{REFERENCES}

1. Jacobaeus, H. C., and Bruce, T., A bronchospirometric study on the ability of the human lungs to substitute for one another. II. Acta med. Scandinav., 1940, 105, 211.

2. Visscher, M. B., and Johnson, J. A., The Fick Principle: Analysis of potential errors in its conventional application. J. Applied Physiol., 1953, 5, 635.

3. Stow, R. W., Systematic errors in flow determinations by the Fick method in Recent Advances in Cardiovascular Physiology and Surgery. Symposium of the Minnesota Heart Association, Minneapolis, Minn., 1954, pp. 30-35.

4. Cournand, A., Mitchell, A., and Fishman, A. P., Applicability of direct Fick method to measurement of pulmonary blood flow during induced acute hypoxia. Federation Proc., 1954, 13, 31.

5. Shepherd, J. T., and Wood, E. H., Oxygen content of pulmonary artery blood in man during various phases of the respiratory and cardiac cycle. Federation Proc., 1954, 13, 135.

6. Fishman, A. P., McClement, J., Himmelstein, A., and Cournand, A., Effects of acute anoxia on the circulation and respiration in patients with chronic pulmonary disease studied during the "steady state." J. Clin. Invest., 1952, 31, 770.

7. Rahn, H., and Bahnson, H. T., Effect of unilateral hypoxia on gas exchange and calculated pulmonary blood flow in each lung. J. Applied Physiol., 1953, $6,105$.

8. Riley, R. L., and Cournand, A., Analysis of factors affecting partial pressures of oxygen and carbon dioxide in gas and blood of lungs: Theory. J. Applied Physiol., 1951, 4, 77.

9. Lilienthal, J. L., Jr., Riley, R. L., Proemmel, D. D., and Franke, R. E., An experimental analysis in man of the oxygen pressure gradient from alveolar air to arterial blood during rest and exercise at sea level and at altitude. Am. J. Physiol., 1946, 147, 199.

10. Fishman, A. P., Studies in man of the volume of the respiratory dead space and the composition of alveolar gas. J. Clin. Invest., 1954, 33, 469.

11. Nisell, O., The influence of blood gases on the pulmonary vessels of the cat. Acta physiol. Scandinav., 1951, 23, 85.

12. Nisell, $O$., Reactions of the pulmonary venules of the cat with special reference to the effect of the pulmonary elastance. Acta physiol. Scandinav., 1951, 23, 361.

13. Fishman, A. P., Himmelstein, A., Fritts, H. W., Jr., Lahoz, F., and Cournand, A., Effect of acute induced hypoxia upon the pulmonary circulation in man. Presented at the Respiration Section, Am. Physiol. Society, April 1954.

14. Aviado, D. M., Jr., Ling, J. S. L., Quimby, C. W., Jr., and Schmidt, C. F., Additional role of reflex pulmonary vasoconstriction during anoxia. Federation Proc., 1954, 13, 4.

15. Wiggers, C. F., Hurlimann, A., and Hall, P. H., Pulmonary blood flow at high altitude. Science, 1953, 117, 473.

16. Moore, R. L., and Cochran, H. W., The effects of closed pneumothorax, partial occlusion of one primary bronchus, phrenicectomy, and the respiration of nitrogen by one lung on pulmonary expansion and the minute volume of blood flowing through the lungs. J. Thoracic Surg., 1932, 2, 468.

17. Dirken, M. N. J., and Heemstra, H., The adaptation of the lung circulation to the ventilation. Quart. J. Exper. Physiol., 1948, 34, 213.

18. Atwell, R. J., Hickam, J. B., Pryor, W. W., and Page, E. B., Reduction of blood flow through the hypoxic lung. Am. J. Physiol., 1951, 166, 37.

19. Peters, R. M., and Roos, A., Effect of unilateral nitrogen breathing upon pulmonary blood flow. Am. J. Physiol., 1952, 171, 250. 